\title{
SALMONELLA: RISCOS, TRANSMISSÃO E CONTROLE NA CADEIA DE PRODUÇÃO SUINA - REVISÃO DA LITERATURA
}

\author{
ZERO, Raphael Chiarelo ${ }^{1}$ \\ RODRIGUES, Jéssica De Oliveira ${ }^{2}$
}

\begin{abstract}
RESUMO: causadores de doenças tóxico alimentares nos seres humanos. Atualmente são conhecidos mais de 2500 sorovares diferentes desta bactéria, sendo os pertencentes à espécie $S$. entérica sub. Entérica, os de maior importância em saúde pública. A salmonelose suína manifesta-se de duas formas distintas, septicemia ou gastroenterite. A primeira, geralmente está associada aos sorovares $S$. Choleraesuis, e $S$. Typhimurium, e a segunda, aos sorovares não adaptados. Alguns fatores estressantes, como o jejum prolongado, viagens por longos períodos, dentre outros, atuam na liberação de cortisol e catecolaminas que por sua vez, elevam a motilidade intestinal, a frequência de defecações e consequentemente a excreção da Salmonella. Existem vários fatores de risco associados à contaminação das carcaças suínas com a Salmonella durante a linha de abate, como por exemplo, a utilização de utensílios contaminados, perfuração e extravasamento de conteúdo gastrointestinal. Sabe-se que a carne suína e seus derivados são considerados importantes fontes da salmonelose humana. Visando a prevenção da ocorrência desta enfermidade, diversas medidas podem ser utilizadas como, por exemplo, a análise microbiológica do produto final, realizada através da quantificação de micro-organismos indicadores, como os aeróbios mesófilos totais (MAT) e as Enterobactérias, ou ainda pela pesquisa de patógenos específicos como Salmonella, e pela aplicação das Boas Práticas de Fabricação (BPF), Procedimentos Padrão de Higiene Operacional (PPHO) e o sistema de Análise de Perigos e Pontos Críticos de Controle (APPCC).
\end{abstract}

Palavras-chave: Salmonelose. Infecção. Carcaça. Contaminação.

SUMMARY: The bacteria of genus Salmonella were identified over a hundred years, an important etiologic agent of food toxic diseases in humans. Currently they are known over 2500 different serotypes of this bacterium, and those belonging to the species S. enterica sub. Enterica, the most important public health. Swine salmonellosis manifests itself in two ways, septicemia or gastroenteritis. The first is generally associated with serovars $S$. Choleraesuis and $S$. Typhimurium, and second, to serovars not adapted. Some stressors such as prolonged fasting, travel for long periods, among others, act in the release of cortisol and catecholamines which in turn, increase intestinal motility, the frequency of bowel movements and therefore the excretion of Salmonella. There are multiple risk factors associated with contamination with Salmonella pig carcasses during the slaughter line such as the use of contaminated utensils, drilling and extravasation of gastrointestinal contents. It is known that pork and its derivatives are considered important sources of human salmonellosis. In order to prevent the occurrence of this disease, various measures may be used such as the microbiological analysis of the final product, performed by quantifying microorganisms indicators such as total aerobic mesophilic (MAT) and the Enterobacteria, or for research specific pathogens such as Salmonella, and the application of Good Manufacturing Practices (GMP), Sanitation Standard Operating Procedures (SSOP) and Hazard Analysis and Critical Control Points (HACCP).

Keywords: Salmonellosis. Infection. Carcass. Contamination.

\section{INTRODUÇÃO}

A suinocultura nacional destaca-se por ser um dos setores mais importantes no agronegócio nacional, ocupando a $4^{\mathrm{a}}$ posição mundial, com aproximadamente 3.471,7 mil

\footnotetext{
${ }^{1}$ Faculdade de Ciências Agrarias e Veterinárias, UNESP Jaboticabal SP.

${ }^{2}$ UNIUBE, Uberaba - MG.
} 
toneladas de carne produzidas anualmente. A carne suína é a terceira proteína animal mais consumida no Brasil, com um consumo médio estimado de 14,6 kg/ano per capita (ABPA, 2015.; BRASIL, 2016).

Entretanto, estudos têm associado à carne suína e seus derivados como fonte de contaminação aos consumidores, pela Salmonella, demonstrando a importância desta para a saúde pública (PISSETI et al., 2012; VAN HOEK et al., 2012).

As bactérias do gênero Salmonella têm ampla distribuição mundial, e estão presentes nos ambientes de produção animal, representando um potencial problema sanitário. Esse gênero é dividido em duas espécies: $S$. bongori e $S$. entérica, sendo $S$. entérica subdividida em seis subespécies: arizonae, diarizonae, houtenae, indica, salamae e entérica. Sendo dividida em mais de 2.500 sorovares, onde os de importância na saúde pública pertencem à S. entérica sub. entérica (FORSYTHE, 2013).

$\mathrm{Na}$ produção de suínos, a contaminação por salmonelas se dá devido à presença de sorovares patogênicos adaptados à espécie suína, responsáveis pela ocorrência de gastroenterites e septicemias, e pelos sorovares adaptados que não causam a doença clínica nos animais, sendo estes, os principais causadores e fontes contaminação das carcaças nos abatedouros, as quais podem posteriormente infectar os humanos (SOBESTIANSKY; BARCELOS, 2012).

Conforme mencionado por Bolton et al., (2002), os suínos atuam como principais fontes de Salmonella para o ambiente do matadouro-frigorífico, tal fato, ressalta a importância do conhecimento das formas de contaminação das carcaças durante o processo de abate.

Dentre as diversas origens de contaminação, destaca-se o contato com utensílios e equipamentos da linha de abate, contato com outras carcaças contaminadas e com conteúdo intestinal que, eventualmente, pode extravasar durante alguma etapa do processo (BUNCIC e SOFOS, 2012). É sabido que o abate, quando realizado de forma adequada do ponto de vista higiênico-sanitário e com a implantação de programas de autocontrole, é capaz de eliminar ou reduzir a níveis aceitáveis a presença de micro-organismos patogênicos como a Salmonella (FORSYTHE, 2013).

Em humanos, a transmissão de Salmonella sp., ocorre principalmente pela ingestão de produtos de origem animal contaminados, o que pode resultar em toxinfecções alimentares, sendo esta bactéria considerada uma das mais importantes causadoras de doença de origem alimentar nos seres humanos (EKPERIGIN; NAGARAJA, 1998).

Neste sentido, a presente revisão de literatura tem como objetivo discorrer sobre as características do gênero Salmonella, os meios de infecção, potencial zoonótico e, principalmente 
sobre a contaminação da carne e produtos cárneos de origem suína, bem como os meios de controle utilizados atualmente.

\section{REVISÃO DE LITERATURA}

\section{$1.1 O$ gênero Salmonella}

O gênero Salmonella pertence ao reino Bacteria, filo Proteobacteria, ordem Enterobacteriales, famila Enterobacteiaceae (KONEMAN et al., 2001). São cocobacilos Gramnegativos, anaeróbios facultativos, geralmente móveis por flagelos peritríqueos (QUINN et al., 2001). Apresentam metabolismo tanto respiratório quanto fermentativo, e seu crescimento ótimo acontece á $37^{\circ} \mathrm{C}$, com pH entre 6,5 e 7,5 (HOLT et al., 1994).

São divididos em duas espécies: S. bongori e S. entérica, sendo a ultima, subdividida em seis subespécies: arizonae, diarizonae, houtenae, indica, salamae e entérica, e em mais de 2.500 sorovares, sendo os pertencentes à S. entérica sub. Entérica, os de maior importância em saúde pública (FRESCHI, 2007; FORSYTHE, 2013).

A classificação desse micro-organismo também se baseia na característica de alguns sorovares serem adaptados a hospedeiros específicos, sendo divididos em dois grupos, os sorovares adaptados e os não adaptados (QUINN et al., 2011).

Os sorovares adaptados e seus respectivos hospedeiros mais comuns são o $S$. Typhi ao ser humano, $S$. Choleraesuis aos suínos, $S$. Gallinarum aos frangos e $S$. Abortus-equi aos equinos. Enquanto que, os não adaptados de maior ocorrência são: Enteritidis, Typhimurium, Anatum, Derby e Panama, que podem infectar diferentes hospedeiros, causando sinais clínicos ou infecções assintomáticas (FRESCHI, 2007; MOXLEY, 2013).

Conforme descrito por Forsythe (2013), os fatores de virulência relacionados a esse gênero são: presença de fimbrias e participação do lipopolissacarideo que auxiliam na aderência e colonização intestinal, e pelo sistema de secreção tipo III, que participa na transferência de diversos sinalizadores bacterianos para o interior da célula hospedeira, induzindo eventos celulares, como o rearranjo da actina dos enterócitos, o que provoca mudanças na superfície celular resultando no surgimento de projeções da membrana citoplasmatica que propicia a macropinocitose da célula bacteriana, além de atuar na transferência de fatores que inibem a fusão do fagossomo com os lisossomos, permitindo que a Salmonella se multiplique, podendo levar à morte celular.

Segundo Hook e Guerrant (1980), o trato gastrointestinal de animais tanto de sangue quente quanto frio atua como principal reservatório desse gênero de bactérias, os quais são eliminados principalmente por via fecal. 


\subsection{Infecção por Salmonella}

A infecção por Salmonella em humanos apresenta-se de três formas distintas, variando de acordo com sorovar envolvido, sendo o sorovar adaptado S. Typhi, o S. Paratyphi e os sorovares não adaptados, responsáveis pela febre tifóide, febre entérica e gastroenterite, respectivamente (PAIM, 2016).

Segundo Gonzales-Escobedo (2010) a febre tifóide é a enfermidade mais prevalente em locais, onde são precárias as condições de saneamento básico. Esta enfermidade está associada à ingestão de alimentos e água contaminada por excrementos de origem humana portadores clínicos ou assintomáticos da doença (CRAWFORD et al., 2010). A doença é caracterizada pela manifestação de sespse, onde tecidos como fígado, baço, intestinos, ossos e vesícula biliar podem ser acometidos, acarretando em sinais clínicos diversos, tais como náuseas, vômito, febre, diarréia, cefaléia, constipação e óbito (GONZALES- ESCOBEDO, 2010; FORSYTHE, 2013).

Como mencionado por Shinohara et al., (2008), a febre entérica apresenta sintomatologia semelhante a da febre tifóide, porém, possui caráter mais brando. A infecção nestes casos ocorre em decorrência do consumo de água e alguns alimentos contaminados como o leite, ovos, mariscos e vegetais.

A gastroenterite ocorre após a ingestão de sorovares não adaptados, sendo o $S$. Enteritidis o mais frequente, entretanto, outros sorovares, como o Typhimurium, Derby, Panama, Schwarzengrund, Infantis, Agona, já foram relatados. (CAPALONGA et al., 2014; PAIM, 2016).

Esta enfermidade é caracterizada pela ocorrência de curso rápido, com manifestação dos primeiros sintomas entre 12 e 36 horas após a ingestão do alimento contaminado, sendo, diarréia, dor abdominal e náuseas os sintomas mais frequentes dessa afecção (FORSYTHE, 2013).

Cerca de 14,7\% dos surtos de Doenças Transmitidas por Alimentos (DTA) no Brasil, são causados pelos sorovares não adaptados de Salmonella, sendo este, o patógeno mais implicado nesta forma de contaminação (BRASIL, 2015). Os principais alimentos contaminados por este agente são os ovos e produtos cárneos (FORSYTHE, 2013).

Dentre os vários alimentos cárneos disponíveis, a carne suína e seus derivados desempenham um importante papel na veiculação da Salmonella, tal fato já foi provado por Fai et al. (2011) em seu estudo, onde foi observado uma presença de 30\% de amostras positivas em 40 peças de presunto suíno cozido, indicando o alto risco de ocorrência de DTA, provinda destes alimentos. Já em estudos utilizando a linguiça frescal de carne suína, 12,8\% (SPRICIGO et al., 2008) e 24\% (MURMANN et al., 2009) das amostras avaliadas apresentaram contaminação por Salmonella, sendo o sorovar Typhimurium o mais prevalente. 
Para que ocorra a infecção em suínos, não é necessária uma alta dose bacteriana do $S$. Choleraesuis, uma vez que como observado por Anderson et al., (2000), em animais experimentalmente infectados com baixas doses bacterianas, 24 horas após a inoculação, constatou-se a presença nas fezes, permanecendo por até 87 dias em leitões. Inicialmente há colonização no íleo e cólon, com posterior invasão de enterócitos, células $\mathrm{M}$ e corrente sanguínea, predispondo à septicemia (PAIM, 2016). Entretanto, a infecção por S. Typhimurium necessita de uma dose infectiva alta, sendo as placas de Peyer, as principais portas de entrada, onde ocorre à invasão por endocitose, atravessando a lâmina basal e alcançando a lâmina própria por exocitose (FEDORKA-CRAY et al., 1995; PAIM, 2016).

As bactérias do gênero Salmonella podem ser viáveis no interior de neutrófilos e macrófagos, podendo alcançar a partir da lamina própria, os linfonodos mesentéricos, além de ter a capacidade de sobreviver em pulmões, fígado, baço, linfonodos e tonsilas (KICH e CARDOSO, 2012).

Segundo Paim (2016), em infecção por sorovares não-adaptados em suínos, apesar de não haver sinais clínicos, os animais tornam-se portadores assintomáticos da bactéria, porém podem excretá-la nas fezes a qualquer momento, principalmente quando submetidos ao estresse.

Verbrugghe et al., (2011) ressalta a característica de alguns suínos infectados por Salmonella, atuarem como portadores assintomáticos, assumindo grande importância na transmissão e disseminação para outros animais do rebanho e para o ambiente pré-abate, atuando como fonte de contaminação de carcaças.

Os portadores assintomáticos podem carrear o agente infeccioso nas tonsilas, intestinos e tecido linfóide por dias, ou até meses, e excretam de forma intermitente um baixo número de Salmonella (KICH; CARDOSO, 2012). Entretanto, frente à situações estressantes há um aumento significativo no numero de agentes patológicos excretados, tal fato esta associado à liberação de catecolaminas, que por sua vez causa o aumento da motilidade intestinal, e consequentemente há uma maior frequência de defecação (BERENDS et al., 1996).

O jejum aos quais os animais são submetidos antes do transporte ou no período pré-abate representa um importante fator estressante, pois leva a um aumento dos níveis do cortisol no sanguíneo, levando ao aumento do número de Salmonella no intestino do portador (VERBRUGGHE et al., 2011).

O transporte dos suínos para o matadouro-frigorífico também caracteriza situação estressante, principalmente quando há manejo inadequado, como por exemplo, superlotação do caminhão e viagens de longa duração (DE BUSSER et al., 2013). 


\subsection{Transmissão na cadeia de produção: Fatores de risco}

Conforme descrito por Paim (2016), diversos fatores de risco já foram identificados para a infecção por Salmonella em suínos, dentre eles podemos citar o tipo de alimento fornecido, o tamanho dos lotes, técnicas precárias de higiene, tipo de instalação, contato entre os animais, dentre outros.

Sabe-se que o tipo de alimento influencia a infecção por esses micro-organismos, visto que, a utilização da ração seca, sólida ou peletizada, causa a diminuição da acidez estomacal, tal fato contribui para a sobrevivência da Salmonella, durante a passagem pelo estomago e posterior colonização no intestino (HEDEMANN et al, 2005.; WILKINS et al., 2010). Já o fornecimento de ração úmida, liquida ou liquida fermentada, diminui o $\mathrm{pH}$ estomacal, reduzindo a sobrevivência e multiplicação dessas bactérias (HOTES et al., 2010).

A ração contaminada pode atuar um veículo de infecção direta dos suínos, uma vez que, equipamentos, ingredientes, caminhões e silos contaminados pela Salmonella, podem infectar a ração (PELLEGRINI et al., 2015).

Com relação ao lote, alguns fatores atuam diretamente na ocorrência de animais soropositivos, dentre eles o tamanho do lote e a origem ou fonte de fornecimento de novos animais, são os de mais importância (PAIM, 2016). Em estudo, Beloeil et al., (2007), demonstrou que em lotes com mais de 2000 animais em fase de crescimento e terminação a soroprevalência foi consideravelmente maior do que em lotes de tamanho médio ou pequeno.

As práticas de higiene aplicadas na granja e nas pocilgas pré-abate influenciam diretamente na ocorrência e transmissão da Salmonella. Lo Go Wong et al., (2004) cita que em granjas com menor grau de higiene, o numero de animais soropositivos foram relativamente maiores quando comparados as que possuíam boas práticas de higiene.

Outro fator de risco importante relacionado à instalação é o tipo de piso das baias, visto que, segundo Hotes et al., (2010) baias com piso vasado, quando comparados a baias com piso liso, apresentaram um maior numero de animais soropositivos para Salmonella.

O contato de animais com baias vizinhas e o tipo de bebedouro também são considerados fatores de riscos importantes relacionados à ocorrência dessa bactéria (PAIM, 2016).

Outro fator de risco importante é o transporte dos suínos para o matadouro-frigorífico, visto que, devido ao intenso estresse à que os animais são submetidos, geralmente há aumento nas taxas de defecação e de excreção do micro-organismos nessa etapa, havendo a contaminação do lote, ambiente e caminhão (DE BUSSER et al., 2013). 
A limpeza e desinfecção dos caminhões de transporte de suínos, geralmente não são eficazes, contribuindo para a ocorrência da infecção dos animais. Em estudo, Swanenburg et al., (2001), observaram que lotes negativos foram infectados durante o transporte para o matadourofrigorífico, ressaltando a ocorrência de infecção dos animais durante o transporte.

A permanência dos suínos nas pocilgas de pré-abate associada ao estresse submetido durante o transporte confere um importante fator de risco, visto que, Segundo De Busser et al., (2013), em seu estudo, observou que 100\% das amostras colhidas em pocilgas de espera de cinco matadouros-frigoríficos, foram positivas para a Salmonella. Em outro estudo realizado em pocilgas vazias, as amostras também foram positivas para a presença dessa bactéria (SWANENBURG et al., 2001). Pesquisas realizadas no Brasil demonstraram que de $25 \%$ a 83,3\% das amostras colhidas em pocilgas de espera, foram positivas (PISSETI et al., 2012).

\subsection{Contaminação das carcaças na linha de abate}

Segundo Bolton et al., (2002) os suínos são a principal fonte de contaminação do ambiente do matadouro-frigorífico, neste sentido deve-se adotar medidas que visem à redução dos níveis de contaminação nas primeiras etapas do abate, como por exemplo, a prática da lavagem dos animais antes de entrar no frigorífico, tal fato reduz consideravelmente os níveis de Salmonella.

A utilização de facas e ganchos contaminados durante a sangria pode causar contaminação nesta etapa do abate, porém a higienização e a troca desses utensílios são medidas simples e eficazes na prevenção das contaminações (BUNCIC; SOFOS, 2012). Durante a escalda, etapa responsável por facilitar a abertura dos poros e a depilação, a carga bacteriana é consideravelmente reduzida, desde que seja realizada em temperatura e tempo corretos, ou seja, de seis a oito minutos em temperaturas superiores a $62^{\circ} \mathrm{C}$ (HALD et al., 2003; WHEATLEY; GIOTIS; MICKEVITT, 2014). Em estudos observou-se que a etapa de escalda reduziu a frequência de carcaças positivas para Salmonella de 30\% para 1\% (BOLTON et al., 2002). Entretanto, para que se alcancem esses valores, é necessária a manutenção da renovação e temperatura da água e tempo correto na etapa de escalda.

A etapa seguinte é o processo de depilação, onde se realiza remoção das cerdas das carcaças. Neste momento pode haver contaminação cruzada devido à dificuldade de limpeza dos equipamentos utilizados (NAMVAR; WARRINER, 2006). Já o chamuscamento reduz as contagens destes micro-organismos em até $2,5 \log 10 \quad \mathrm{UFC} / \mathrm{cm} 2$, devido à exposição a temperaturas de até $100^{\circ} \mathrm{C}$, por aproximadamente 15 segundos (WHEATLEY; GIOTIS; MICKEVITT, 2014). Na etapa de polimento, as cerdas remanescentes são removidas, entretanto neste momento há aumento das contagens microbianas em $1,5 \log 10$ UFC/cm2, em decorrência 
da presença residual de bactérias no equipamento ou nas carcaças (PEARCE et al., 2004; BUNCIC; SOFOS, 2012).

Segundo Wheatley, Giotis e Mickevitt (2014) pode haver um aumento significativo nas contagens de MAT e de Enterobactérias após a etapa de evisceração, devido à contaminação das carcaças em decorrência de possíveis rupturas de vísceras e contaminação por matéria fecal, além do risco de contaminação cruzada pela utilização de facas e ganchos contaminados (BERENDS et al., 1997; BUNCIC; SOFOS, 2012).

Uma medida eficaz na prevenção da contaminação na linha de abate e das carcaças, por material fecal e micro-organismos como a Salmonella, é a oclusão do reto dos animais (BORCH; NESBAKKEN; CHRISTENSEN, 1996; DE BUSSER et al., 2013).

\section{5 medidas de Controle higiênico-sanitário na contaminação de carcaças}

São várias as formas que podem ser utilizadas no controle da contaminação das carcaças, como por exemplo: a análise microbiológica do produto final, realizada através da quantificação de micro-organismos indicadores, como os aeróbios mesófilos totais (MAT) e as Enterobactérias, ou pela pesquisa de patógenos específicos como a Salmonella (PAIM, 2016), além da utilização de algumas medidas como as Boas Práticas de Fabricação (BPF), Procedimentos Padrão de Higiene Operacional (PPHO) e o sistema de Análise de Perigos e Pontos Críticos de Controle (APPCC) (FORSYTHE, 2013).

Os microrganismos indicadores, a enumeração de MAT e das Enterobacterias, são utilizados para indicar a qualidade microbiológica, higiênico-sanitária e presença de grupos específicos de micro-organismos, como a Escherichia coli e a Salmonella, indicando uma possível contaminação de origem fecal, ou condições sanitárias inadequadas durante o processamento, produção e armazenamento dos alimentos (ADAMS; MOSS, 2005).

Devido às características desses grupos de micro-organismos indicadores, a legislação brasileira preconiza através da Circular No 175/2005/CGPE/DIPOA, que as indústrias de alimentos, dentre elas a da carne, realizem um controle microbiológico periódico dos seus procedimentos, bem como da matéria prima utilizada (BRASIL, 2005).

Os limites pré-estabelecidos na enumeração de MAT para produtos cárneos na União Europeia são: aceitável, valores inferiores a $4 \log \mathrm{UFC} / \mathrm{cm} 2$ de MAT; inaceitável, valores superiores a $5 \log \mathrm{UFC} / \mathrm{cm} 2$. Para as Enterobactérias os limites devem ficar abaixo de $2 \log$ $\mathrm{UFC} / \mathrm{cm} 2$ e não devem ultrapassar $3 \log \mathrm{UFC} / \mathrm{cm} 2$. Quando amostras apresentam valores entre os limites aceitáveis e inaceitáveis, devem ser tomadas medidas de correção na indústria (EU, 2005). 
No Brasil, o limite para Salmonella, em um ciclo amostral realizado semestralmente, é de cinco positivas em um total de 50 carcaças. Já para as Enterobactérias o aceitável é a presença de até $2 \times 10^{2} \mathrm{UFC} / \mathrm{cm}^{2}$, a partir desse valor, a amostra é classificada como inaceitável. Para MAT o valor aceitável é de até 5 x $103 \mathrm{UFC} / \mathrm{cm}^{2}$, os valores acima deste, são considerados inaceitáveis (BRASIL, 2007).

O emprego das Boas Práticas de Fabricação (BPF) tem o intuito de gerar um alimento com padrão de qualidade higiênico-sanitário aceitável, a partir de um conjunto de procedimentos básicos, como o controle de saúde dos funcionários, matérias primas, visitantes, estrutura dos estabelecimentos, higiene e a manipulação. (FORSYTHE, 2013).

A legislação brasileira através da Portaria no 368/1997/MAA estabelece as condições higiênico-sanitárias e de boas práticas de elaboração para estabelecimentos elaboradores e industrializadores de alimentos, e os princípios que devem ser adotados com relação à procedência da matéria-prima, instalações, limpeza dos estabelecimentos, higiene de pessoal e requisitos sanitários, higiene na elaboração do produto alimentício além do armazenamento e transporte de matérias primas e dos produtos acabados (BRASIL, 1997).

Os Procedimentos Operacionais Padronizados (POP) e os Procedimentos Padrão de Higiene Operacional (PPHO) são documentos que descrevem e padronizam as instruções das operações e a frequência de execução das atividades realizadas na indústria, e descrevem de forma detalhada todas as etapas que devem ser seguidas em procedimentos de higienização de equipamentos, utensílios ou ambientes de processamento (TONDO; BARTZ, 2011).

Entretanto, durante o processo de abate, existem particularidades que dificultam a identificação do momento exato para a verificação dos procedimentos de limpeza, como no caso das facas, serras e alicates que devem ser lavados e sanificados, através da imersão em esterilizadores a $82^{\circ} \mathrm{C}$ por 20 segundos após cada operação. A contaminação das carcaças por conteúdo gastrintestinal durante a evisceração e divisão das carcaças também se enquadram nestas particularidades (BRASIL, 2005).

Segundo Paim (2016), o sistema APPCC é uma ferramenta utilizada na indústria de alimentos e tem como principal finalidade garantir a segurança dos alimentos no que tange à perigos químicos, físicos e biológicos. Este método se baseia na identificação, avaliação e controle dos perigos, garantindo a inocuidade do alimento (FORSYTHE, 2013).

Conforme descrito na circular 369/2003, os pontos críticos de controle mínimos no abate são, a contaminação de carcaças por ingesta, leite ou matéria fecal e a temperatura da carcaça ao final do resfriamento (BRASIL, 2003).

Com relação à contaminação das carcaças com bactérias intestinais como a Salmonella, durante o abate, as medidas de controle e prevenção são baseadas na limpeza e desinfecção de 
utensílios e das máquinas durante a depilação e polimento. Outras etapas que buscam a redução dos níveis bacterianos com a utilização de processos que envolvem temperaturas elevadas por determinado período de tempo, são a escaldagem e flambagem (FORSYTHE, 2013). Segundo Borch, Nesbakken e Christensen, (1996) a contaminação pela serra utilizada na divisão das carcaças pode ser minimizada através do controle de velocidade na linha de abate e pela temperatura da água de lavagem.

\section{CONSIDERAÇÕES FINAIS}

A Salmonella é considerada a principal bactéria relacionada às doenças tóxicoalimentares dos seres humanos, sendo os produtos de origem animal, em especial a carne suína e seus derivados, importantes vinculadores deste patógeno. A identificação e eliminação de suínos portadores, bem como a prevenção e adoção de medidas higiênico-sanitárias nas granjas, caminhões, pocilgas pré-abate, e durante toda linha de produção são de extrema importância na redução da disseminação da bactéria e da contaminação das carcaças. Deve-se evitar situações estressantes, como por exemplo, o jejum prolongado, a superlotação e o transporte por longos períodos, visto que, nestas ocasiões há um aumento nas taxas de defecação e eliminação da Salmonella, elevando a ocorrência da disseminação e contaminação do ambiente e dos suínos.

\section{REFERÊNCIAS}

ABPA - ASSOCIAÇÃO BRASILEIRA DE PROTEINA ANIMAL. Relatório Anual. SP, 2015. Disponível em:< http://abpabr.com.br/setores/suinocultura/publicacoes/relatorios-anuais > Acesso em: 07 out. 2016.

ADAMS, M. R; MOSS, M. O. Methods for the microbiological examination of foods. Food Microbiology. London, Cap. 10., 2ª ed, p. 370-394, 2005.

ANDERSON, R. C. et al. Assessment of the long-term shedding pattern of Salmonella sorovar choleraesuis following experimental infection of neonatal piglets. Journal of Veterinary

Diagnostic Investigation. Columbia, v. 12, p. 257-260, 2000.

BELOEIL, P.A. et al. Risk factors for Salmonella soroconversion of fattening pigs in farrow-tofinish herds. Veterinary Research. Les Ulis, v. 38, p. 835-848, 2007.

BERENDS, B.R. et al. Identification and quantification of risk factors in animal management and transport regarding Salmonella spp. in pigs. International Journal of Food Microbiology. Amsterdam, v. 30, p. 37-53, 1996.

BOLTON, D.J. et al. Washing and chilling as critical control points in pork slaughter hazard analysis and critical control point (HACCP) systems. Journal of Applied Microbiology. Oxford, v. 92, p. 893-902, 2002. 
BORCH, E.; NESBAKKEN,T.; CHRISTENSEN, H. Hazard identification in swine slaughter with respect to foodborne bacteria. International journal of food microbiology. Amsterdam, v. 30, p. 9-25, 1996.

BRASIL. Ministério da Agricultura e do Abastecimento. Portaria n ${ }^{\circ} 368$ de 04 de setembro de 1997. Regulamento Técnico sobre as condições Higiênico-Sanitárias e de Boas Práticas de Fabricação para Estabelecimentos Elaboradores/Industrializadores de Alimentos. Brasília, DF, 1997. 12p.

BRASIL. Ministério da Agricultura, Pecuária e Abastecimento. Circular no 369 de 02 de junho de 2003. Instruções para elaboração e implantação dos sistemas PPHO e APPCC nos estabelecimentos habilitados à exportação de carnes. Brasília, DF, 2003. 11p.

BRASIL. Ministério da Agricultura, Pecuária e Abastecimento. Circular no 175 de 16 de maio de 2005. Procedimentos de Verificação dos Programas de Autocontrole. Brasília, DF, 2005.39 p.

BRASIL. Ministério da Agricultura, Pecuária e Abastecimento. Notícias. Crescimento da classe média no mundo gera demanda por alimentos perecíveis e geladeiras. Disponível em:

$<$ http://www.agricultura.gov.br/comunicacao/noticias/2016/01/crescimento-da-classe-media-nomundo-gera-demanda-por-alimentos-pereciveis-e-geladeiras> Acesso em: 01 out 2016.

BUNCIC, S.; SOFOS, J. Interventions to control Salmonella contamination during poultry, cattle and pig slaughter. Food Research International. Barking, v. 45, p. 641-655, 2012.

CAPALONGA, R. et al. Salmonella serotypes, resistance patterns and food vehicles of salmonellosis in southern Brazil between 2007 and 2012. Journal Infect. Dev. Ctries. v. 8, p. 811-817, 2014.

CRAWFORD, R.W. et al. Gallstones play a significant role in Salmonella spp. Gallbladder colonization and carriage. PNAS, v. 107, p. 4353-4358, 2010.

DE BUSSER, E. V. et al. Salmonella control in live pigs and at slaughter. The Veterinary Journal. London, v.196, p.20-27, 2013.

EU - EUROPEAN COMISSION. Commission Regulation no 217 of 7 March 2014. Amending Regulation $n^{\circ}$ 2073/2005 as regards Salmonella in pig carcases. Official Journal of the European Union, Bruxelas, v. 69, p. 93-94, 2005.

EKPERIGIN H.E.; NAGARAJA K.V. Salmonella. Microbiology Food Borne Pathoges, v.14, p.17-29, 1998.

FAI, A. E. C. et al. Salmonella sp e Listeria monocytogenes em presunto suíno comercializado em supermercados de Fortaleza (CE- Brasil): Fator de risco para saúde pública. Ciência ; Saúde Coletiva. Rio de Janeiro, v. 16, p. 657-662, 2011.

FEDORKA-CRAY, P. J. et al. Alternate Routes of Invasion May Affect Pathogenesis of Salmonella Typhimurium in Swine. Infection and immunity. Washington, v. 63, p. 2658-2664, 1995.

FORSYTHE, S. J. Ferramentas de gestão da segurança de alimentos. In: FORSYTHE, S. J.

Microbiologia da Segurança dos Alimentos. $2^{\mathrm{a}}$ ed. Porto Alegre: Artmed, 2013. Cap. 8, p. 375389. 
FRESCHI, C. R. Investigação experimental sobre a transmissão aerógena e naso-nasal de Salmonella entérica subespécie entérica sorotipo Derby em suínos. 2007, 60F Tese (Doutorado) Universidade Estadual Paulista-UNESP, Campus de Jaboticabal.

GONZALES-ESCOBEDO, G. et al. Chronic and acute infection of the gall bladder by Salmonella Typhi: Understanding the carrier state. Progress, v. 9, p. 9-14, 2010.

HALD, T. et al. The occurrence and epidemiology of Salmonella in European pig slaughterhouses. Epidemiology and Infection. Cambridge, v.131, p. 1187-1203, 2003.

HEDEMANN, M. S. et al. Effect of feed particle size and feed processing on morphological characteristics in the small and large intestine of pigs and on adhesion of Salmonella enterica sorovar Typhimurium DT12 in the ileum in vitro. Journal of Animal Science. Champaign, v. 83, p. $1554-1562,2005$.

HOLT, J.G. et al. Bergey's manual of determinative bacteriology. 9.ed. Baltimore: Williams ; Wilkins, 1994. Cap.5: Facultative anaerobic Gram-negative rods: p. 175-189.

HOOK, E.; GUERRANT, R. Harrision's principales of internal medicine. 9.ed, McGraw-Hill, New York, NY, p.641-648, 1980.

HOTES, S. et al. Risk Factors for Salmonella Infection in Fattening Pigs - An Evaluation of Blood and Meat Juice Samples. Zoonoses and Public Health. Berlin, v. 57, p. 30-38, 2010.

KICH, J. D. ; CARDOSO, M. Salmonelose. In: SOBESTIANSKY, J. ; BARCELLOS, D. Doença dos suínos. 2. ed. Goiânia: Cânone, 2012, p. 257-264.

KONEMAN, E. W. et al. Enterobacteriaceae. diagnostico microbiológico: texto e atlas colorido, 5.ed, Rio de Janeiro: Guanabara Koogan, 2001. p. 177-262.

LO FO WONG, D. M. A. et al. Herd-level risk factors for subclinical Salmonella infection in European finishing-pig herds. Preventive Veterinary Medicine. Amsterdam, v. 62, p. 253-266, 2004.

MOXLEY, R. Enterobacteriaceae: Salmonella. IN: MCVEY, S. D.; KENNEDY, M.; CHENGAPPA, M. M. Veterinary Microbiology. 3 ed., John Wiley ; Sons, 2013. Cap. 8, p. 75 84.

MURMANN, L.; DOS SANTOS, M. C.; CARDOSO, M. Prevalence, genetic characterization and antimicrobial resistance of Salmonella isolated from fresh pork sausages in Porto Alegre, Brazil. Food Control. Guildford, v. 20, p. 191-195, 2009.

NAMVAR, A.; WARRINER, K. Application of enterobacterial repetitive intergenic consensuspolymerase chain reaction to trace the fate of generic Escherichia coli within a high capacity pork slaughter line. International Journal of Food Microbiology. Amsterdam, v. 108, p. 155-163, 2006.

PAIM, S. D. Perfil de excreção de Salmonella em suínos ao abate e presença de carcaças positivas no pré-resfriamento. 2016. 54F. Dissertação (Mestrado) Universidade Federal do Rio Grande do Sul, Porto Alegre, RS. 
PEARCE, R. A. et al. Studies to determine the critical control points in pork slaughter hazard analysis and critical control point systems. International Journal of Food Microbiology. Amsterdam, v. 90, p. 331-339, 2004.

PELLEGRINI, D. C. P. et al. Distribution of Salmonella clonal groups in four Brazilian feed mills. Food Control. Guildford, v. 47, p. 672-678, 2015.

PISSETI, C. et al. Detecção de Salmonella enterica e Listeria monocytogenes em carcaças suínas na etapa de pré-resfriamento. Acta Scientiae Veterinariae. Porto Alegre, v. 40, p. 1-8, 2012.

QUINN, P. J. et al. Veterinary Microbiology and Microbial Disease. 2. ed. Iowa: Wileyblackwell, 1231 p., 2011.

SHINOHARA, S. et al. Salmonella spp., importante agente patogênico veiculado em alimentos. Ciência ; Saúde Coletiva. Rio de Janeiro, v. 13, p. 1669-1674, 2008.

SOBESTIANSKY, J.; BARCELOS, D. Doença dos suínos. 2.ed.Goiania,Copyright,2012. 995 p.

SPRICIGO, D. A. et al. Prevalência e perfil de resistência a antimicrobianos de sorovares de Salmonella isolados de linguiças suínas tipo frescal em Lages, SC. Arquivo Brasileiro de Medicina Veterinária e Zootecnia. Belo Horizonte, v. 60, p. 517-520, 2008.

SWANENBURG, M. et al. Salmonella in slaughter pigs: the effect of logistic slaughter procedures of pigs on the prevalence of Salmonella in pork. International Journal of Food Microbiology. Amsterdam, v. 70, p. 231-242, 2001.

TONDO, E. C. ; BARTZ, S. Microbiologia e sistemas de gestão da segurança de alimentos. Porto Alegre: Sulina, 2011, 263 p.

VAN HOEK, A. H. A. M. et al. A quantitative approach towards a better understanding of the dynamics of Salmonella spp. in a pork slaughter-line. International Journal of Food Microbiology. Amsterdam, v. 153, p. 45-52, 2012.

VERBRUGGHE, E. et al. Stress induced Salmonella Typhimurium recrudescence in pigs coincides with cortisol induced increased intracellular proliferation in macrophages. Veterinary Research. Les Ulis, v. 42, p. 01-10, 2011.

WHEATLEY, P.; GIOTIS, E. S.; MCKEVITT, A. I. Effects of slaughtering operations on carcass contamination in an Irish pork production plant. Irish Veterinary Journal. Dublin, v. 67, p. 01-06, 2014.

WILKINS, W. et al. Distribution of Salmonella serovars in breeding, nursery, and grow-to-finish pigs, and risk factors for shedding in ten farrow-to-finish swine farms in Alberta and Saskatchewan. The Canadian Journal of Veterinary Research, v. 74, p. 81-90, 2010. 
